\title{
Models of Hedging the Price Risk of Raw Materials: A Literature Review
}

Mandeng Ma Ntamack Jules*

Faculty of Economics, Applied Management of the University of Douala, Douala, Cameroon

\begin{abstract}
This article highlights a set of model risk management in commodity prices since the pioneering work of Yamey in 1951 to the most resents contributions. Only hear were taken into account theoretical models and in a nonexhaustive way, but grouped into three streams of reflection (the traditional models, modern approaches and recent contributions). The models place particular emphasis on the behaviour of suppliers of raw materials to the risk of price and seek ultimately to stabilize commodity prices turn an acceptable average. But the results obtained through various tests of these models show the apparent ineffectiveness of these and give reason to the market. This confirms the theory of efficient markets, in the sense that no one can beat it.
\end{abstract}

Keywords: Model; Price risk; Courses; Raw material; Stabilization; Efficiency; Market

\section{Introduction}

The management of the price risk of raw materials has been an object of reflection since the works of Yamey [1]. Several models have been proposed but they have always violated market rules which make the volatility of prices and render the different techniques proposed to be inefficient in the coverage of price risk. The different studies carried out to measure the efficiency of coverage operations lead to contradictory results. Certain conclusions are very surprising. They establish that certain professionals carry out hedging operations on the futures market can lead to losses that are more than those they were bearing when they did not hedge against price risk.

It is surprising that professionals operate in the futures market at a loss. These conclusions are very difficult to accept says Working [2], that the futures market very often used and appreciated by professionals who do not complaint of their inefficiency. In reality, it is not the efficiency of the hedging operations that is the cause, but the conception made by economists and financial experts on the hedging operations [3]. This article presents analysis and criticises the different methods and models proposed by researchers to hedge against the volatility of the prices of raw materials on the futures commodity market. On one hand we present the traditional and modern approaches of hedging against price risk and on the other hand their recent contributions.

\section{Modern and Traditional Hedging Methods: What Should be Retained?}

Since the 1950's, researchers have always raised the problem of hedging financial and non-financial assets such as stocks of raw materials and basic commodities. Debates relative to these have progressed from a traditional perspective of hedging such as simple operations to cover a long or short position, to a modern reflection integrating methods of portfolio management. The presentation and critical analysis of these two approaches will be developed below.

\section{The traditional conception of hedging}

The traditional concept of hedging can be understood by presenting it on one hand and questioning it on the other hand.

The presentation of the traditional conception of hedging: The traditional conception of hedging is very quickly perceived when one glances at the existing literature. Thus, going back to the 1950s, we can mention the definition given by Yamey [1]. In fact, in a study based on the different forms of hedging, this author defines hedging in the following way: "...if a processor or a dealer buys a quantity of commodity, he takes up a long position in the spot market, and he is exposed to the risk of loss should price fall before he sells. He hedges by selling a future contract of the same quantity, there taking up a short position in the futures market" [1] $]^{1}$. Hieronymus [4] defines hedging as follows: "Risks are shifted by the process of hedging. To hedge is to take a position in futures equal and opposite to an existing cash position". In the traditional conception, hedging is perceived as being essentially motivated by the need to reduce the risk of variation in prices at the counter. The futures derivatives market is therefore perceived as an insurance market. Thus, from the traditional perspective a hedging operation will be considered as efficient only when the future prices and the prices at the counter evolve together. The operation is considered as perfect when the result of the hedging is zero. In other words, a hedging operation will be considered as perfect only if the difference between the base at closure and the base when it opens is zero. In these conditions if we consider $\mathrm{P}_{0}$ the price at the counter at time $0, \mathrm{P}_{1}$ the over the counter price at period $1, \mathrm{f}_{0}$ the future price at period 0 for delivery at period 1 , and $f_{1}$ the spot price prevailing on the future market at the end of the contract, whereas for a hedging operation to be considered as perfect in the traditional conception of hedging, then [5]:

$$
\left(\mathrm{p}_{1}-\mathrm{p}_{0}\right)-\left(\mathrm{f}_{1}-\mathrm{f}_{0}\right)=\left(\mathrm{p}_{1}-\mathrm{f}_{1}\right)-\left(\mathrm{p}_{0}-\mathrm{f}_{0}\right)=0 \text {. }
$$

Where: $\left(p_{1}-f_{1}\right)$ corresponds to the base of closure whereas $\left(p_{0}-f_{0}\right)$ is the base when it opens, that is when the operation begins.

It is by considering the concept of futures market as an insurance market that Keynes and Hicks elaborated the theory of normal deport. However, the theory of normal deport does not require that the result of the hedging operation be zero for it to be considered as perfect. Thus, in the 1963, Wise attracted attention on the ironical character of

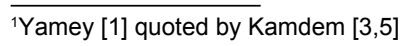

*Corresponding author: Mandeng Ma Ntamack Jules, Faculty of Economics, Applied Management of the University of Douala, Douala, Cameroon, Tel: 7746 6966/99810462; E-mail: jamandeng2005@yahoo.fr

Received October 27, 2014; Accepted November 25, 2014; Published December 05, 2014

Citation: Jules MMN (2014) Models of Hedging the Price Risk of Raw Materials: A Literature Review. Int J Econ Manag Sci 3: 206. doi: 10.4172/2162-6359.1000206

Copyright: ( 2014 Jules MMN. This is an open-access article distributed under the terms of the Creative Commons Attribution License, which permits unrestricted use, distribution, and reproduction in any medium, provided the original author and source are credited. 
the traditional perception of hedging. In 1961, Gray, for the first time proposed empirical results which will enable Working [6] to put into question the concept of "hedging-insurance against risk" [5].

Working's criticism of the concept of traditional hedging': Working [6], after realising that the concept of traditional hedging was insufficient to explain all the Operations of speculation, distinguished five types of hedging according to the objective of the arbitragist; he distinguishes hedging aimed at profits from stocking, operational hedging, selective hedging, anticipative hedging and hedging aimed at a reduction of price risk. Thus, Working introduces the concept of "multipurpose hedging" or multiple motivation hedging. Therefore according to the author hedging aimed at profits from stocks is used when the operator speculates on the differential of the price (future price and over the counter price) and consequently stocks to benefit from the differential. This type of hedging will generally be used by negotiators whose benefit are directly associated to the evolution of prices. As for operational hedging, it is done when break even stock are constituted by the negotiators or the manufacturers within the framework of their current activities. It should be noted however that it is often difficult to determine the quantity of goods necessary for current activities of the operator, such that it will be difficult to distinguish between the stock that is said to be operational and speculative stock. As concerns selective hedging it is carried out in consideration of future price evolutions. Thus, when operations of hedging are carried out selectively, we will have cases in which the position taken on the futures market is less than that which is found on the over the counter market, but we could equally have cases of "over hedging" that is cases in which the position taken on the futures market is more than the position held on the over the counter market. With selective hedging, the operations are arbitragist and speculative. Such as the case of selective hedging in which anticipative hedging is also carried out on the basis of anticipations relative to future prices. However, with the difference of selective hedging anticipative hedging is an operation that is essentially destined to be substituted temporally to a commercial operation to be realised in the future.

Anticipative hedging can take the form of the purchase of a futures contract by a manufacturer with the aim of hedging against the stock of raw material to be bought in the future or the form of sales of future contracts by producers before the harvest. As concerns hedging as a means of protection against price risk, which seems to have played an essential role during the first years of the creation of the futures market continue to play a primordial role.

This concept of multipurpose hedging of Working [6] is a fundamental contribution to the theory of futures markets since it has hedging operations or considered the traditional theory by supposing that hedging enables to bring the results of the operation to the required level "break-even point" whereas logically a national operator will want to take advantage of all the opportunities offered by the futures market to maximise his revenue. The current literature on futures operations follows that of Working [6] by integrating the portfolio approach.

\section{The modern approach to hedging: The portfolio approach}

The modern perception of all operations on the futures market is that according to the terms of Telser [7], an economic agent "receiver of income" of the same degree as any other economic agent. However, if the objective of the operator is only to maximise his revenue, then he would realise important gains if his anticipations are correct. But

${ }^{2}$ The presentation of different techniques of hedging below had as base Kamdem [5] and completed by our findings from 1990. on the contrary, his anticipations of the operator or not correct then he would lose a lot. In these conditions and according to Telser [7], one can think that the operator will try to maximise his income despite the risk involved [5]. After the works of Telser, the modern approach of hedging is carried out in terms of risk-return, returns being the mathematical experience of the income of the producer and the risk, being measured by the standard deviation of income. The modern perception of hedging can in essence be viewed through the model of Johnson and Kinnon as well as the path traced by other authors.

The model of johnson et de McKinnon: In the model of Johnson ([8], quoted by [5]), a primary market is defined with respect to the position of the operator. The primary market according to him is the market on which the operator is supposed to earn a living (make his life). Therefore according to the later it corresponds to the physical market. In these conditions, let's consider Xi the position in physical units of the operator on the over the counter market; then, in order to minimise risk of price variation between for example period $t_{1}$ and period $t_{2}$ during which the position on the over the counter market remains open, the arbitragist is supposed to take a future position $\mathrm{X}_{\mathrm{i}}$ on the market $j$ (secondary market). Let's call $r_{i}$ the variation in price on market $i$ between $t_{1}$ and $t_{2}$; then the return associated to holding a position Xi on market $\mathrm{i}$ (primary market) and a position $\mathrm{Xj}$ on market $\mathrm{j}$ (secondary market) will be equal to:

$$
\mathrm{R}=\mathrm{X}_{\mathrm{i}} \mathrm{R}_{\mathrm{i}}+\mathrm{X}_{\mathrm{j}} \mathrm{r}_{\mathrm{j}}
$$

The expected return is equal to: $E(R)=X_{i} \mu_{i}+X_{j} \mu_{j}$

The variance of the return is equal to:

$$
\mathrm{V}(\mathrm{R})=\mathrm{X}_{\mathrm{i}}^{2} \delta_{\mathrm{i}}^{2}+2 \mathrm{X}_{\mathrm{i}} \mathrm{X}_{\mathrm{j}} \text { Covij }+\mathrm{X}_{\mathrm{j}}^{2} 2 \sigma_{\mathrm{j}}^{2} \text {. }
$$

Where $\mu_{\mathrm{i}}$ and $\mu_{\mathrm{i}}$ are respectively the anticipated variations of prices on the physical market and the anticipated variations on the futures market between $t_{1}$ and $t_{2}$.

$\sigma_{i}^{2}$ and $\sigma_{j}^{2}$ are respectively the variance of price variations between $t_{1}$ and $t_{2}$.

$\mathrm{Cov}_{\mathrm{ij}}$ is the co-variance between the returns of Xi and those of $\mathrm{X}_{\mathrm{j}}$.

If we derive $\mathrm{V}(\mathrm{R})$ with respect to $\mathrm{Xj}$ and solve the equation for $\mathrm{X}_{\mathrm{j}}$, we can determine the optimal proportion $X_{j}^{*}$ to be taken on market $j$ to minimise the variance. We will then have:

$$
\begin{aligned}
& \mathrm{dV}(\mathrm{R}) / \mathrm{dX}_{\mathrm{j}}=2 \mathrm{X}_{\mathrm{i}} \operatorname{Cov}_{\mathrm{ij}}+2 \mathrm{Xj} \sigma_{\mathrm{j}}^{2}=0 \\
& \Rightarrow \quad \mathrm{X}_{\mathrm{j}}^{*}=-\mathrm{X}_{\mathrm{i}} \operatorname{Cov}_{\mathrm{ij}} / \sigma_{\mathrm{j}}^{2}
\end{aligned}
$$

Equation (5) tells us that, if the future price is positively correlated with the over the counter price, the position to be taken on the secondary market will be equal to the reverse of the open position on the primary market; this result is identical to the prescriptions on the traditional theory. However, a difference in six exists between the model of Johnson and the traditional theory, in the sense that the quantity of physical goods that has to be hedged is not the same in the two analyses.

In fact, from Equation (5), we can deduce:

$$
\mathrm{X}_{\mathrm{j}}^{*} / \mathrm{X}_{\mathrm{i}}=-\operatorname{Cov}_{\mathrm{ij}} / \sigma_{\mathrm{j}}^{2}
$$

From Equation (6), it appears that if the ratio $\operatorname{Cov}_{i j} / \sigma_{j}^{2}$ is equal to 1 , then $X_{j}^{*}=-X_{j}$ and we get the results of the traditional theory. However, from equation (6), it is clear that given the variation of the covariance between $r j$ and $r_{i}$, the ratio $\operatorname{Cov}_{i j} / \sigma_{j}^{2}$ can be more than 1 and in this case hedging on the futures market will be more than the open physical position; if $\operatorname{Cov}_{\mathrm{ij}} / \sigma_{\mathrm{j}}^{2}$ is less than 1, then part of the stock of the operator 
might not be hedged without being sub-optimal. All these conclusions remain true as long as the future prices evolve in the same sense as the over the counter prices and this seems to be the case generally [9]. However, it can happen that in some cases, the future prices evolve in the opposite direction with respect to the over the counter price; in these conditions, the position to take on the futures market by the arbitragist who is a risk minimiser is supposed to be the same as the open position on the over the counter market, but such an operation is eliminated by the traditional theory of hedging. If in equation (5) we replace $\mathrm{Xj}$ by its optimal value $\mathrm{X}_{\mathrm{j}}^{*}$, we will have:

$$
\mathbf{V}(\mathbf{R})^{*}=\mathrm{X}_{\mathrm{i}}^{2} \sigma_{\mathrm{i}}^{2}-2 \mathrm{X}_{\mathrm{i}}^{2}\left(\operatorname{Cov}_{\mathrm{ij}} / \sigma_{\mathrm{j}}\right)^{2}+\mathrm{X}_{\mathrm{i}}^{2}\left(\operatorname{Cov}_{\mathrm{ij}} / \sigma_{\mathrm{j}}\right)^{2} \Rightarrow \mathbf{V}(\mathbf{R})^{*}=\mathrm{X}_{\mathrm{j}}^{2} \sigma_{\mathrm{i}}^{2}\left(1-\rho^{2}\right)
$$

From equation (4), we can say that the hedging will be more efficient than it renders $V(R)$ minimum; we will say that it is perfect if $\tilde{\mathrm{n}}$ is close to 1 , since in this case, $\mathrm{V}(\mathrm{R})=0$. If we call $\ell$ the coefficient of efficiency of hedging, we can write as from equation (7).

$$
\ell=1-\mathrm{V}(\mathrm{R})^{*} / \mathrm{X}_{\mathrm{i}}^{2} \sigma_{\mathrm{i}}^{2}
$$

The model of Johnson is the pioneering model in the domain of the determination of the optimal ratio of hedging, given that all the past literature is inspired from it. Nevertheless, the model of Johnson has some limits since it cannot be applied in the case of producers of raw materials who would take positions on the futures market. We had to wait for McKinnon [10] for the analysis to be extended to producers of basic commodities.

The model of McKinnon [10] is based essentially on five hypotheses namely: the farmer can hedge himself only by future sales, production is not known when the decision relative to intervention on the market is taken; moreover, technical opportunities are supposed to be fixed, the future price at which the farmer sells his futures contract is an average to long term spot price, the decision period is a year and covers two successive harvest periods, transaction costs do not exist and normal deport does not exist either such that the future price is equal to the over the counter price that prevails at the end. The model of McKinnon is written as follows:

Given R, the income of the farmer during the harvest period; then we can write:

$$
\mathrm{R}=\mathrm{PX}+(\mathrm{f}-\mathrm{P}) \mathrm{X}_{\mathrm{F}},
$$

Where $\mathrm{X}$ is the quantity, $\mathrm{X}_{\mathrm{F}}$ the quantity sold in the future, $\mathrm{P}$ the spot price and $f$ the future price. The expected income of the farmer is equal to:

$$
\mathrm{E}(\mathrm{R})=\mathrm{E}(\mathrm{PX})+\mathrm{X}_{\mathrm{f}}[\mathrm{f}-\mathrm{E}(\mathrm{P})]=\mathrm{E}(\mathrm{PX}) .
$$

The variance of the income of the farmer will consequently be:

$$
\mathrm{V}(\mathrm{R})=\mathrm{E}\left\{\left[\mathrm{PX}+(\mathrm{f}-\mathrm{P}) \mathrm{X}_{\mathrm{f}}\right\}-\mathrm{E}(\mathrm{PX})^{2}\right.
$$

If we assume that $\mathrm{X}$ and $\mathrm{P}$ follow a bivariate normal distribution described by the parameters $\mu_{\mathrm{X}}, \sigma_{\mathrm{X}}, \mathrm{f}, \sigma_{\mathrm{P}}$ et $\rho$ we can write, after some transformations:

$$
\mathrm{V}(\mathrm{R})=\mathrm{f}^{2} \sigma_{\mathrm{X}}^{2}+\mu_{\mathrm{X}}^{2} \sigma_{\mathrm{P}}^{2}-2 \mathrm{f}\left(\mathrm{X}_{\mathrm{f}}-\mu_{\mathrm{x}}\right) \operatorname{Cov}(\mathrm{X}, \mathrm{P})+\left(1-\rho^{2}\right) \sigma_{\mathrm{X}}^{2} \sigma_{\mathrm{P}}^{2}-2 \mathrm{X}_{2} \mu_{\mathrm{X}} \sigma_{\mathrm{p}}^{2}+\mathrm{X}_{\mathrm{f}}^{2} \sigma_{\mathrm{p}}^{2}(
$$

If we derive equation (12) with respect to $X_{f}$ and cancel the results obtained by solving the equation obtained, the optimal quantity $\mathrm{X}_{\mathrm{f}}^{*}$ will be equal to:

$$
\begin{aligned}
& \mathrm{dV}(\mathrm{R}) / \mathrm{dX}_{\mathrm{f}}=-2_{\mathrm{f}} \operatorname{Cov}(\mathrm{X}, \mathrm{P})-2 \mu_{\mathrm{X}} \sigma_{\mathrm{P}}^{2}+2 \mathrm{X}_{\mathrm{f}} \sigma_{\mathrm{P}}^{2}=0 \\
& \Rightarrow \quad \mathrm{X}_{\mathrm{f}^{\prime}}=\left[\mathrm{f} \operatorname{Cov}(\mathrm{X}, \mathrm{P})+\mu_{\mathrm{X}} \sigma_{\mathrm{P}}^{2}\right] / \sigma_{\mathrm{P}}^{2}=\mathrm{f}\left[\operatorname{Cov}(\mathrm{X}, \mathrm{P}) / \sigma_{\mathrm{P}}^{2}\right]+\mu_{\mathrm{x}} .
\end{aligned}
$$

The optimal ratio of hedging with respect to the expected output (harvest) is therefore equal to: $\mathrm{X}_{\mathrm{f}} / \mu_{\mathrm{x}}=\mathrm{f}\left(\operatorname{Cov}(\mathrm{X}, \mathrm{P}) / \sigma_{\mathrm{P}}^{2} \mu_{\mathrm{x}}\right]+1$

From this last equation, we find that if $\rho=0$, in order words, if there is no correlation between the prices and the quantities, then $X_{f} / \mu_{x}=1$ and we get back the results of the traditional theory. However, one can think that this case will be rare and that logically in normal conditions, $\rho$ will certainly be between -1 and 0 , such that $\mathrm{X}_{\mathrm{f}} / \mu_{\mathrm{x}}$ will always be less than 1 ; moreover for $\rho$ that is sufficiently negative and $\sigma_{\mathrm{x}} / \mu_{\mathrm{x}}$ sufficiently big with respect to $\sigma_{\mathrm{p}} / \mathrm{f}$, the ratio $\mathrm{X}_{\mathrm{f}} / \mu_{\mathrm{x}}$ will be negative; in this case, the optimal strategy of the producer will be to buy contracts on the futures market instead of selling them as indicated by the traditional theory. Here, the producer has to behave like a speculator.

The model of McKinnon [10] is of vital importance since it explicitly treats the case of producer of raw materials whereas until recently the authors were bent on analysing speculating operations of industrialists and negotiators of raw materials. The model of McKinnon however has limits since it is assumed that the base of closure is zero which is a contestable hypothesis [5].

The orientation path followed by the other analysis based on the E-V model (Experience-Variance): The analysis carried out after the works of Johnson and McKinnon generally retain the same hypotheses as those of the two authors. Some of these analyses assume, following Johnson that the only uncertainty is found at the level of future prices. Other such as the analysis of McKinnon assumes that price variations and quantities are random. Ward and Fletcher [11] attempted a general approach of Johnson and McKinnon so as to take into account the case of long and short term hedging operations and the case of pure speculative operations of farmers and negotiators. Anderson and Danthine [12], showed that routine hedging (perfect hedging) is suboptimal since it ignores the opportunities of speculative profits. Peck [13] uses the E-V mode to empirically determine the optimal hedging ratio on the market of fresh eggs on Chicago Mercantile Exchange (CME). The conclusion from all these studies is that on the futures market the intervention of the producer-arbitrage will be motivated partially by the desire to stabilise his income and by the desire to maximise this income, such that the position the he will take on the futures market will be a mixture of hedging and pure speculation ${ }^{3}$.

The recurrent debate in all these analyses is that nothing is said about the behaviour of the producer on the physical market, moreover we can think that a producer who takes gains will hedge against risk in the futures market only based on the position held in the physical market, Consequently, the hedging decision cannot be analysed independently of the sales strategies adopted by the producer on the physical market thus the contribution of Kamdem [5], of the CNUCED [14] and of Mandeng [15].

\section{The Strategies of Producer when Faced with Price Risk: Multipurpose Contributions}

The contributions of Kamdem [3,5], of the CNUCED [14] and those of Mandeng [15]; have a particularity which is that of making producers of raw materials to intervene on the physical and futures markets or simply use information from the futures commodity market to elaborate hedging strategies against the price risk of their products. Therefore in this second part, we are going to present these approaches of hedging as well as their limits.

${ }^{3}$ When the optimal hedging ratio is determined, it can indicate for a given physical position that exactly an equivalent quantity of futures contract has not been taken into account. 


\section{The hedging strategies of producers according to the model of two sequence intervention}

The model of two sequence intervention [3,5]; is inspired directly from the model of Johnson [8]. The originality of the two sequence model lies in the fact that it does not only explicitly take into account the objective of minimisation of the income risk of the producer at the level of each sequence, but it equally enables the producer to take advantage of all the profit opportunities on the futures and over the counter markets. This model enables to reduce the specific or diversified risk in sequence 1 . At the level of sequence 2 , it enables to reduce the systematic or non-diversified risk ${ }^{4}$.

The First Sequence of the decision: In this first sequence, the producer is supposed to have as objective to minimise the risk associated to the portfolio of position for a given level of income. We will therefore have the following programme:

$$
\Sigma_{1}\left\{\begin{array}{l}
\text { Minimise } \mathrm{V}\left(\mathrm{R}_{\mathrm{C}}\right)=\mathrm{X}^{\prime} \mathrm{CX}_{\mathrm{X}} \\
\text { On the following contraints : } \\
\mathrm{E}\left(\mathrm{R}_{\mathrm{C}}\right)=\mathrm{X}^{\prime} \mathrm{E}(\mathrm{P}) \geq \mathrm{R}_{\mathrm{C}}^{*} \\
\mathrm{X} \geq 0
\end{array}\right.
$$

Where $\mathrm{X}=\left(\mathrm{X}_{0}, \mathrm{X}_{1}, \ldots \mathrm{X}_{\mathrm{n}}\right)^{\prime}$ is a vector-column representing the different of physical positions taken on the over the counter market. The sign (') indicates the transpose of a vector. It is the matrix of variancecovariances of the different positions taken on the over the counter market. It is a matrix $(\mathrm{n}+1, \mathrm{n}+1) . \mathrm{E}(\mathrm{P})=\left[\mathrm{P}_{0}, \mathrm{E}(\mathrm{P} 1), \ldots, \mathrm{E}(\mathrm{Pn})\right]^{\prime}$ is a vector-column representing the expected unit sales prices of $n+1$ batches of goods. $\mathrm{k}$ is a vector-column $(\mathrm{n}+1,1)$ with all components equal to 1 . The resolution of $\left(\Sigma_{1}\right)$ enables us to determine the vector $\mathrm{X}^{*}=\left(\mathrm{X}_{0}^{*}, \mathrm{X}_{1}^{*}, \ldots \mathrm{X}_{\mathrm{n}}^{*}\right)^{\prime}$ of optimal batches that the producer can sell on the over the counter market on each delivery date $i[3,5]$. After the first sequence, the producer can decide not to take hedging positions on the futures market under these conditions his income as well as the risk attached to it will be evaluated at this level. However, he can equally decide to take positions on the futures market and consequently move to the second sequence of the program.

The Second sequence of the decision: In this sequence, the Producer is supposed to minimise the risk (variance) of the income associated to each portfolio $\pi_{\mathrm{i}}$ of mixed positions (positions taken on the over the counter market). Given objective income that he fixed on one hand and on the other hand the volume of the optimal batch $\mathrm{X}_{\mathrm{i}}^{*}$ determined in sequence 1 . The programme to be resolved by the producer in this second sequence is

$$
\text { As follows: } \Sigma_{2}\left\{\begin{array}{l}
\text { Minimise } \mathrm{V}\left(\mathrm{R}_{\mathrm{i}}\right)=\mathrm{X}_{\mathrm{i}}^{2} \mathrm{~V}\left(\mathrm{P}_{\mathrm{l}}\right)+\mathrm{y}_{\mathrm{i}}^{2} \mathrm{~V}\left(\mathrm{f}_{1}\right)+2 \mathrm{X}_{1} \mathrm{y}_{\mathrm{i}} \operatorname{Cov}\left(\mathrm{P}_{\mathrm{i}}, \mathrm{f}\right) \\
\text { Under the following contraints : } \\
\mathrm{E}\left(\mathrm{R}_{\mathrm{i}}\right)=\mathrm{X}_{\mathrm{i}} \mathrm{E}\left(\mathrm{P}_{\mathrm{i}}\right)+\mathrm{y}_{\mathrm{i}} \mathrm{E}\left(\mathrm{f}_{\mathrm{i}}\right) \geq \mathrm{R}_{\mathrm{i}}^{*} \\
\mathrm{X}_{\mathrm{i}}=\mathrm{X}_{\mathrm{i}}^{*} \\
\mathrm{y}_{i} \text { with contraint of sign }
\end{array}\right.
$$

The resolution of $\left(\Sigma_{2}\right)$ enable the producer to determine $y_{i}^{*}$, the optimal position of hedging for a given physical batch i. Consequently $\mathrm{n}$ interactions are necessary to determine all the optimal positions of hedging given that the last $\mathrm{n}$ physical batches determined in sequence 1 , are stocked and consequently have to be hedged by positions taken on the futures market.

${ }^{4}$ According to the portfolio theory, the total risk of an asset has two components namely: systematic or non-diversification risk and non-systematic or diversifiable risk of assets; in a portfolio it is possible to cancel the diversifiable risk.
This model applied to the Parisian market of cacao and cafe with the goal of finding out whether the producer who will behave according to prescriptions of the model could effectively reduce fluctuations while maximising income lead to the conclusion that; "on these markets, the MIDS appears as an instrument that can be used by the producer who intends to reduce the fluctuations of his income (assuming the quantity produced to be known without paying a high price for this stabilisation [3].

Despite the results, the model of two sequence intervention (MTSI) has some limits first at the level of its hypotheses which are high in number (10 hypotheses) and some can be left out: this would be the case with the hypotheses relative to a zero initial stock in the model, the reasoning is carried out within a period (seasons for our producer), the elimination of this hypotheses necessitates the construction of a dynamic model in which the optimal quantity (stock) to be transferred from one season to another would be determined from year to year [5]. Finally the MTSI had as objective to stabilise the income of the producer, an objective which is not pursued today both nation and worldwide since we cannot claim to stabilise an entity in a fluctuating environment. Thus, the contribution of CNUCED [14] and Mandeng [15].

\section{The income models}

The attempts of intermediation between producers of the south and the futures commodity markets always lead to sub-optimal solutions [16]. This made researchers to make producers responsible when it comes to price risk. Thus recent studies place the producer at the heart of hedging actions by assuming that he can either intervene directly on the market or use information on the price of his product to elaborate an optimal hedging strategy as carried out by CNUCED [14] and Mandeng [15] as shown below.

The Hedging Strategies of producers according to the model of CNUCED: The CNUCED [14], within the framework of its research programme launched since the liberalisation of the trade of basic commodities under the theme: "Liberalisation of the trade of basic commodities and management of price risk"; carried out several studies in producer countries and depend on the product these products. The most important of these studies seems to be that carried out by Uganda titled: "the introduction of new risk management schemes to the producers of Robusta and Arabica cafe in Uganda. This study correspond to the scientific reflection of Johnson, Mc Kinnon, Kamdem and other authors and adopts the technique of risk management associated to the analysis of basic convergence, the level of production and the degree of risk aversion of the producer. Here, we will consider only one hedging scheme: the optimal hedging of the producer, since the hypotheses retained namely: the futures market is efficient, the hedging concerns a future over the counter sales, the quality of the product is indicated to be that of the futures contract, production is not flexible in the short term, the producer is averse to risk and his behaviour is represented within the framework of an average-variance model; seem to correspond to the reality and the possibilities of management of price risk in developing countries far away from the futures market and respect operational conditions which exist in the countries of the south. Thus, within the framework of a producer with a non-flexible production in the short term which is not random, there is no basic risk; the behaviour in the face of risk is represented by a mean-variance [14]:

$$
\pi_{\mathrm{P}}=\mathrm{P}_{1} \mathrm{Q}+\left[\mathrm{T}(1,0)-\mathrm{P}_{1}\right] \mathrm{X}_{\mathrm{P}}-\mathrm{FQ}-\mathrm{CF} .
$$


Where : $\mathrm{Q}$ is exogenous production, $\mathrm{X}_{\mathrm{p}}$ is the future position, $\mathrm{CF}$ represents fixed production costs, $\mathrm{P}_{1}$ is the spot price on due date, $\pi_{\mathrm{P}}$ is the revenue of the producer, $T(1,0)$ is the future price on due date $t_{1}$ of the contract sold at $t_{0}$, FQ is the total cost of commissions (or total commission charges).

The objective of the producer is: $\operatorname{Max} E\left[\mathrm{U}\left(\pi_{\mathrm{P}}\right)\right]$ with $\mathrm{U}(\mathrm{X})=\mathrm{f}(\mathrm{E}(\mathrm{X})$; $\operatorname{VAR}(\mathrm{X})$.

Despite the clarity of the model it was not tested for the analysis of results and it includes Ugandan producers on the futures market which is not very evident since intervention on the market not only requires financial, technical and managerial capacity but also proximity and the tradition of intervention on the market. This in our very humble opinion is not easy for the producers in the south. Thus, the necessity to use information on price to put in place a good strategy for the producers of the south.

Hedging strategies for producers according to Mandeng's Model: Other studies carried out in Cameroon ${ }^{5}$ and in other developing countries, propose other models such as the income model. This model tries to stabilise the sales or purchase price through the sharing of the differential (difference between the price expected in the contract and the real price on the day of execution of the contract) between the seller and the buyer.

The formulation of the income model has several stages namely: the specification of variables, the mathematical formulation of the model, the estimation of the parameters and the test of the significance of the model and parameters. In the specification of the variables of the income model, the following notations were adopted:

- $\mathbf{R}=$ Income of the cacao and/or cafe cooperative. It is an exogenous or explanatory variable.

- $\mathbf{Q}=$ the quantity produced of cacao and/or cafe. It is known and fixed, thus it does not influence the model.

- $\mathbf{P}_{\mathbf{t}}=$ the future price on due date $t_{1}$ of the contract sold at $t_{0}$. It is an explanatory or exogenous variable of the model. It is also called expected value or expected price.

- $\quad \mathbf{P s}=$ The spot price (the future over the counter price). It is not an explanatory or exogenous variable of the model but is used to calculate the premium (bonus). It is equallycalled real value or real Price.

- $\mathbf{P}_{-01}$ ou $\mathbf{P}^{\prime}=$ Premium obtained from the difference between $\mathrm{P}_{t}$ and Ps. It is also an exogenous variable of the model and can be positive or negative. Already knowing the proportion of the premium to be negotiated; we can formulate the income model. The model takes the following form.

$$
-\mathrm{R}_{\mathrm{t}}=\mathrm{c}+\mathrm{a}_{1} \mathrm{QP}_{\mathrm{st}}+\mathrm{a}_{2} \mathrm{QVP}_{\mathrm{t}}^{\prime}+\mathrm{e}_{\mathrm{t} \text {. }}
$$

In this formulation, we know that $\mathrm{Q}$ which is the production is known and fixed and $\mathrm{V}^{6}[15]$ which was calculated and which represents the value of the game is equally known. The income model in which the income of the producer is uniquely a function of variables Pst and P't. Thus the following new specification:

$$
R_{t}=c+a_{1} P_{s t}+a_{t}^{\prime} 25 \% P_{t}^{\prime}+E_{t}
$$

${ }^{5}$ Mandeng [15], The management of price risk by the producers of raw materials an application to Cameroon cooperatives of cacao and café, Ph.D thesis University of Douala Cameroon, 317p..

${ }^{6}$ By using the strategy game theory we find that it is $25 \%$ of the differential that stabilises the sales or purchase price of the product.
Where: $\mathbf{R}_{\mathbf{t}}$, is the revenue of the corporative at time e $t, \mathbf{P}_{\mathbf{s t}}$, is the highest future price among all the other prices of the period $t, \mathbf{2 5 \%} \mathbf{P}_{t}$, is the proportion of the premium to be negotiated in the case where there is a difference between the expected price and the counter price (even a negative difference), $\mathrm{a}_{1}$ et $\mathrm{a}_{2}$, are the parameters of the income model $\mathbf{C}$, is the constant of the income model $\mathbf{E}_{\mathbf{t}}$ is the specification error of the income model. It is the difference between the true model and the specified model. This error is unknown; $\mathrm{x}$ is the number of observations corresponding to the due date of futures contracts of cacao and cafe. It does not appear in the model but helps in testing the model. The specification of the model verifies the hypotheses of linearity, of observation of variables without error of the independence of errors etc.

This model was tested both on its significance and its volatility and shows that they can be used to stabilise the prices of raw materials. Despite being operational this model in the context of the south requires some prerequisites namely: restructuring of funding schemes, training of producers, availability of information on the price on real time basis [15].

\section{Commentaries and Conclusions: The Inefficiency of the Models to the Realities of the Market}

The pioneering articles of McKinnon [11], Peck [13] and that of Rolfo [17], are based on the intervention of producers on the futures market are common in that the authors assume that the producer takes the decision to hedge before harvest when there still exist the uncertainty on the quantity that will effectively be sold on the market. Moreover, it is implicitly assumed in these studies that futures and over the counter operations are carried out simultaneously and the producer is supposed to put all his products on the market once the harvest is over. These hypotheses which can be justified in the case of products that cannot be stored such as fresh eggs in Peck's analysis, do not seem to be realistic when the product cannot be stored (in the analysis of Rolfo [17]). In fact if the product can be stored, an arbitrage who takes a hedging position before harvest will have unnecessary hedging charges at the end given that during the harvest the situation is unfavourable on the market. The alternative of storage remains and nothing seems to oblige the arbitrage to sell over the counter just after the harvest [5]. The other orientation paths followed by the other analysis based on the experience-variance model $[5,11,12,14]$ seem to make the producer to intervene directly on the futures market by passing through the over the counter market (the case of Kamdem's model). But it is established that on the futures and over the counter markets only specialists intervene since the techniques and instruments to be manipulated to hedge against price risk are so complex that their use does not often ensure the gains (profits) but equally the losses even for professionals ${ }^{7}$ on one hand and on the other hand the markets (futures and physical are found in consumer countries that are far away from producers of the South. There is therefore not only the problem of distance but also the practices of such markets for the producers of the South. The later do not have neither the managerial nor the technical means to realise this. The hedging models presented so far are of less importance to the producers of the South on one hand and on the other hand, it seems that a producer whose strategy is based on these models will generally be a producer who has an infinite aversion for risk since such a behaviour reflects the attitude of an economic agent who minimises risk but who does not seem to have gains given the situation. However, it is clear

${ }^{7}$ We can support this argument by the failure of the Bogota group which bought futures contracts to hedge against the risk of fall in price but the market made the contrary. 
Citation: Jules MMN (2014) Models of Hedging the Price Risk of Raw Materials: A Literature Review. Int J Econ Manag Sci 3: 206. doi: 10.4172/2162-6359.1000206

Page 6 of 6

that at a given level of risk, an ordinary economic agent will endeavour to use all the possibilities available so as to maximise his income. With all these limits, it seems logical to think that in other to maximise his income, a rational producer should choose the most fruitful periods during which they can sell profitably by observing future prices which reveal future over the counter prices and by negotiating if possible a risk premium since the bearer of the risk holds the stock. Thus, the proposal of revenue model which is a function of future price and premium [15].

Finally, the analysis of the hedging technique through the presentation of hedging models since that of Yamey [1] to recent models shows the willingness of researchers to propose models which lead to the regulation and stabilisation of basic commodity prices at an acceptable proportion. But sudden variations in prices persist rendering the model presented so far inefficient. On the contrary in practice operators succeed in carrying out profitable operations. This shows that there are possibilities to formalise practices on the basic commodities market and develop coherent models which integrate practical aspects and theoretical aspects of the hedging of price risk. This confirms the necessity and pertinence of this domain in the finance of markets.

\section{References}

1. Yamey BS (1951) Short hedging and long hedging in futures markets: Symmetry and asymmetry. Journal of Law and Economics 14: 413-434.

2. Working H (1958) The theory of anticipation prices, American Economic Review Proceeding 188-210.

3. Kamdem D (1990) Marché à terme de marchandises et réduction du risque du producteur dans le cadre d'un modèle à deux séquences, Economie Appliquée. Tome 4: 165-178.

4. Hieronymus TA (1997) Economics of futures trading of commercial and personal profit, Commodity Research Bureau, New York 143-160.
5. Kamdem D (1986) Marchés à terme de marchandises et stabilisation du revenu du producteur de matières premières : Application au cacao et au café sur la place de Paris, Thèse de Doctorat d'Etat en Sciences de Gestion, Universite de Rennes I, Paris 348

6. Working $\mathrm{H}$ (1962) New concepts concerning futures markets and prices, AER PP. 431-459.

7. Telser LG (1981) Margins and futures contracts, The Journal of Futures Markets 225-253.

8. Johnson LL (1960) The theory of hedging and speculation in commodity futures markets, Review of Economic Studies 139-151.

9. Simon $Y(2001)$ Marchés dérivés des matières premières et gestion du risque de prix, Paris, Economica 2ndedn 341.

10. McKinnon RL (1967) Futures markets, buffer stock and income stability to primary producers. Journal of Political Economy 801-820.

11. Ward RW, Fletcher LB (1971) From hedging to pure speculation: A micro mode of optimal futures and cash market position. American Journal of Agricultura Economics 71-78.

12. Anderson RW, Danthine JP (1983) The time pattern of hedging and volatility of futures prices. Review of Economics Studies 249-266.

13. Peck AE (1975) Hedging and income stability: Concept Implication and an Example, JPE 57: 410-419.

14. CNUCED (2004) Introduction de nouveaux schémas de gestion du risque de prix auprès des producteurs de café robusta en Ouganda, Genève 36.

15. Mandeng MNJ (2013) La gestion du risque de prix par les producteurs de matières premières: une application aux coopératives camerounaises de caca et de café, Thèse de Doctorat Ph.D en sciences de gestion, Université de Douala 317.

16. Simon $Y$ (1989) Les marchés à terme dans le monde et leur utilité pour les opérateurs, Matières Premières et Echanges Internationaux, Paris, Economica 33-74.

17. Rolfo J (1980) Optimal hedging and price uncertainty: The case of cacao producer, JPE 88: 100-116. 